\title{
A sedução de Império: surrealismo versus verossimilhança no viés da ficção televisiva
}

Robéria Nádia Araujo Nascimento ${ }^{1}$ 


\section{Resumo}

Este texto, derivado de uma pesquisa em andamento ${ }^{2}$, problematiza a teledramaturgia e suas funções narrativas, entrecruzando-se com a observação de alguns elementos que perpassam a telenovela Império e outras tramas de Aguinaldo Silva. Como embasamento teórico, dialoga com as proposições de Gordillo (2010), Martín-Barbero (2004; 2014), Bulhões (2009), Paiva (2010) e Lopes (2009), a fim de compreender as estratégias de verossimilhança e surrealismo que permeiam o universo da ficção e o tornam fértil ambiente de fruição para os sentidos plurais que mobilizam o imaginário coletivo. Aborda a concepção de realismo fantástico, na tentativa de pensar quais estratégias midiáticas fomentam a ressonância e a mediação das tramas, que despertam novos sentidos de inteligibilidade do cotidiano sociocultural. Por fim, sugere aportes teóricometodológicos para possíveis análises de produtos ficcionais seriados.

\section{Palavras-chave}

Narrativas ficcionais, teledramaturgia, mediações culturais, surrealismo, verossimilhança. 
This text, derived from an ongoing study, questions the television drama and its narrative functions, crisscrossing with the observation of some elements that permeate the telenovela Império and other plots of Aguinaldo Silva. As theoretical basis, it dialogues with the hypothesis of Gordillo (2010), Martín-Barbero (2004; 2014), Bouillon (2009), Paiva (2010), and Lopes (2009), in order to understand the likelihood and surrealism strategies that permeate the universe of fiction and make it into a fertile environment for enjoyment of the plural meanings that mobilize the collective imagination. This text discusses the design of fantastic realism, in trying to think of what media strategies foster resonance and the mediation of the plots, which awaken new directions for understanding the sociocultural everyday life. Finally, it suggests theoretical and methodological contributions to possible fictional series product reviews.

\section{Keywords}

Fictional narratives, soap operas, cultural mediations, surrealism, likelihood. 


\section{Por trás da tela: preâmbulos da abordagem}

Eu sou dos que pensam que a cultura do ver é menos a paisagem que vemos que o olhar com o qual vemos

(Martín-Barbero)

Vivemos a cultura da tela em todas as suas expressões, diversidade de dispositivos, identidades e fluxos, assimilando seus impactos multifacetados. Nesse tempo de visualidades e invisibilidades, no qual a tecnologia sofistica os sentidos humanos e muitas vezes superficializa as relações, a TV se mantém viva como experiência do sensível que se converte em espaço de encontro das trajetórias socioculturais das maiorias. "É na tela da TV que se produz a mais ampla e permanente transformação da cotidianidade social e cultural cujos protagonistas são os excluídos" (MARTÍN-BARBERO, 2014, p. 11).

Ao avaliar os impactos audiovisuais na educação, o teórico da comunicação e da cultura nos diz, otimista, que a TV aguça o nosso olhar para as mazelas e dilemas do mundo, permanecendo na condição de veículo popular, ao incluir e democratizar saberes e fazeres, dada a sua imensa penetração entre todos os públicos e gostos ao redor do mundo. Paiva (2010), produzindo uma instigante análise "estética e social" da ficção televisiva, argumenta que a telenovela seduz por representar uma das possibilidades efetivas de expansão dos sentidos, pois funciona como janela que exibe diversos aspectos de um Brasil real, por meio de "afetos, sensações e sentimentos, que geram modalidades de percepção, memória e conhecimento [...]. As imagens e sons das telenovelas levam à formação de vínculos, aproximações e interações entre os atores sociais" (p. 13).

A telenovela Império, com sua polissemia de "falsos brilhantes" narrativos, espelha uma cultura cindida entre a oferta desenfreada de informação e a carência de compreensão no interior dela (GALENO; CASTRO; SILVA, 2003), ao contextualizar uma sociedade que produz enfrentamentos em nome da ambição. Por isso, vários aspectos se somam para justificar o interesse pela trama de 
Aguinaldo Silva ${ }^{3}$, que repete nesse folhetim, como já fez em outros, uma aliança com o realismo fantástico. Encantos, desencantos, humores, desafetos, sentimentalismos exacerbados, encontros e desencontros permeiam os fatos insólitos mostrados no horário nobre, enveredando pela atmosfera surreal que também marcou trabalhos de grande audiência do escritor, a exemplo $A$ indomada (1997) e Pedra sobre pedra (1992).

A propósito das narrativas fantásticas e mencionando de modo pertinente o dramaturgo Dias Gomes, para quem a tradução da realidade brasileira não poderia se abster da magia, do fantástico e do sobrenatural, Paiva (2010) assinala que "o imaginário televisual do país capta e expressa com vigor os matizes de uma nação híbrida, sincrética e dionisíaca" (p. 15), em uma analogia ao mito de Dionísio, arquétipo que manifesta a transgressão, a alegria, a transcendência, características que se conectam com a natureza humana, facilmente despertada para o oculto, o sobrenatural e o desconhecido, bem como para as demais simbologias que permeiam o imaginário coletivo. Assim, como sugere a epígrafe deste texto, trata-se de uma coletividade "permissiva" que consome ilusões, inerentes à cultura do ver, mas que, na verdade, pouco "enxerga" a respeito da sociedade contemporânea.

O autor estreou em 1984, no horário nobre da Rede Globo, em uma parceria com Glória Perez na novela Partido alto. Nos anos 1990, registram-se os seus primeiros grandes sucessos de audiência em autoria individual: Tieta (1989), Pedra sobre pedra (1992), A indomada (1997), Suave veneno (1999). Em 2001, Porto dos milagres, adaptação das obras de Jorge Amado: Mar Morto e A descoberta da América pelos turcos, seguida por Senhora do destino (2004), Duas caras (2007-2008), Fina estampa (2011-2012). Em seus trabalhos, observamos as estratégias de erotismo e comicidade cruzadas com a paródia, além do tratamento caricato em relação aos homossexuais: os personagens Teodoro Pereira (Paulo Betti), da recente Império, e o mordomo Crô (Marcelo Serrado), de Fina Estampa. Sua teledramaturgia é permeada por abordagens que revelam o embate entre ricos corruptos e pobres honestos, cidadãos defensores da ética e das relações afetivas, delineando sociabilidades que emergem nos subúrbios e nos ciclos abastados da sociedade (Na novela Império, observamos os laços de solidariedade que permeiam as amizades do Comendador José Alfredo com o núcleo pobre e trabalhador da comunidade de Santa Tereza. Indícios das cumplicidades e afinidades dos personagens de níveis socioeconômicos diferentes, mas que mantêm em comum o gosto pela simplicidade na vida). Contudo, as vilãs também são grandes destaques de suas tramas: Cora, em Império; Perpétua, em Tieta; Altiva, em A indomada, e Nazaré Tedesco, em Senhora do destino são atemporais e mobilizam indignações coletivas com suas crueldades, tornando os produtos ficcionais hábeis na capacidade de "midiatizar a maldade humana", ainda que sob o exagero das tintas da fantasia. São criações e artifícios da marca autoral de Aguinaldo Silva, também eficiente na ressonância de heróis e anti-heróis inesquecíveis que representam nas suas histórias facetas inerentes aos grupos sociais que compõem a cultura do nosso país. 
Retomando Martín-Barbero (2014), encontramos o pensamento oportuno de que a linguagem é vetor de mediação cultural, ao mesmo tempo em que é perpassada de signos e prenha de símbolos, não se prestando à fria análise das suas estruturas. É essa linguagem simbólica que reaquece e contamina tudo com o excesso e o conflito de interpretações. Na ótica do autor, a ficção, por meio de suas narrativas, simboliza o mundo. O sentido, portanto, depende da percepção do todo que se oculta em cada sujeito, manifestado pela linguagem, capaz de configurar a cultura como algo polifônico e plural, espaço múltiplo de criação e recriação da sociedade, multifacetado em suas idiossincrasias, e que foge aos padrões estabelecidos ao ser reinventado. Assim, as palavras de Carvalho (2003) nos parecem apropriadas para explicar a simbologia do processo cultural em sua busca pelo novo: "No esforço de subjetivação e objetivação de si é que o sistema cultural se incumbe de vitalizar as experiências poéticas da criatividade, para que as experiências prosaicas da repetição do real não sucumbam à sua própria mesmice" (p. 12).

Nessa perspectiva, a arte da ficção, para Martín-Barbero (2014), tornase resposta à historicidade, e para Carvalho (2003) representa as recriações da cultura, a sedução da visibilidade, a comunicação e a criatividade das ideias, por mais absurdas que pareçam, porque forjam narrativas que contribuem para um mundo menos fragmentado e mais lúdico, no qual se torna possível inventar o impossível, ao menos na tela da TV.

Além da ideia de completude e complementação, ligadas à historicidade cultural, Martín-Barbero (2014) salienta que o símbolo na cultura do ver é uma provocação, faz pensar, "dá o que pensar". Seguindo a trilha dos argumentos expostos, percebemos que os símbolos do fantástico na ficção cumprem a missão de transgredir a versão oficial da realidade, que busca encontrar "explicações" para os acontecimentos sociais e seus dilemas apenas pela via da racionalidade. Os elementos irracionais, em contrapartida, destoam dessa lógica e desconstroem as epifanias do cotidiano, tornando-se presentes na obra de 
Aguinaldo Silva ${ }^{4}$ para nos instigar à refletividade. Em Pedra sobre pedra (1992), o personagem Sérgio Cabeleira (Osmar Prado) uiva como um lobo e se sente fortemente atraído pela lua cheia. Lola (Tânia Alves) mantém o irmão preso em uma jaula para protegê-lo dessa maldição e evitar que ele cometa loucuras nessa fase do mês. Apesar disso, o irmão parte em direção ao satélite no final da novela, desaparecendo diante de seus olhos. Abordar a esquizofrenia pela analogia da lua se mostrou um recurso estético que trouxe mais poesia ao drama de exclusão vivido pelo personagem, sensibilizando o público que se acostumou ao estranhamento provocado por ele. A adoção do realismo fantástico emerge no folhetim para pensar a loucura, o que sugere mais leveza ao tratamento da questão.

A vida e a morte do fotógrafo sedutor Jorge Tadeu (Fábio Júnior), mostradas na mesma novela, são etapas que também merecem destaque, uma vez que repercutiram intensamente no período de exibição da trama ${ }^{5}$, época em que as novelas precisavam de uma boa trama, pois não contavam com a ressonância das redes sociais nem com os efeitos especiais sofisticados de hoje. Úrsula Pontes (Andréa Beltrão) é outro exemplo de realismo fantástico: a moça se utiliza dos cristais para se comunicar com o Além, por isso é a primeira pessoa que mantém contato com o espírito do fotógrafo após a sua morte. Contudo, nem o fim da vida afetou a trajetória de sucesso do personagem, uma vez que Jorge Tadeu continuou aparecendo para as mulheres, que se apaixonavam ao comerem uma flor que brotava do seu túmulo. A estranha espécie, nascida da fértil imaginação de Aguinaldo Silva, tinha "propriedades afrodisíacas" (PEDRA SOBRE PEDRA, 1992).

A sucessão de cativantes personagens da vertente fantástica movimentou a trama. Dona Quirina (Miriam Pires) é uma senhora lúcida que, apesar dos memoriaglobo.com, globo.com e no novo canal dedicado ao entretenimento da emissora: gshow.com. 
120 anos de idade, surpreende pela memória prodigiosa ao saber de todos os acontecimentos de Resplendor, cidade fictícia na qual se passa a novela Pedra sobre pedra. Cândido Alegria (Armando Bogus) é transformado em pedra no final da história, talvez em uma analogia à rigidez de sua perversidade. Em $A$ indomada (1997), um incêndio faz a vilã cômica Altiva (Eva Wilma) se transfigurar em uma bruxa assustadora. A ventania que devastou Santana do Agreste em Tieta (1989) foi outro recurso "apocalíptico" utilizado pelo autor para impactar o público no último capítulo.

Todavia, nosso interesse aqui recai sobre Império, onde mais uma tentativa de realismo mágico pode ser verificada através da personagem Cora (vivida inicialmente por Drica Moraes ${ }^{6}$ ). A vilã da trama "rejuvenesce" de repente, após colocar um véu preto, surgindo em cena a atriz Marjorie Estiano, que a interpretou na primeira fase do folhetim. Sua interação com os demais personagens ocorre como se o fato de "trocar de pele" causasse certo estranhamento só nos primeiros momentos, mas fosse incorporado com naturalidade por todos com o passar do tempo. Observamos que a criatividade de Aguinaldo Silva não tem medidas e resvala para as licenças poéticas similares as dos contos de fada.

De acordo com Bulhões (2009), o realismo fantástico, alma da concepção de surrealismo, muito recorrente nas tramas mencionadas, pode ser considerado uma ponte de aproximação com a realidade, uma vez que promove associações com fatos críveis, embora os conecte com um mundo fascinante que pertence à fantasia e à imaginação. De acordo com o autor, existe um laço entre ficção, sonho e devaneio, que diz respeito às necessidades subjetivas universais e atemporais da fantasia. A subjetividade da ficção é que se transmuta no surreal, e este comunica e traduz desejos inerentes ao humano, por evocar sensibilidades: "O sonho e as metáforas são dimensões que desestabilizam as relações lógicas e racionais que regem nossa vida na vigília" (p. 18). 
Todavia, como sugere Almeida (2003), as metáforas não se reduzem ao seu papel de ampliar a compreensão dos temas que queremos conhecer; são operações de pensamento que conduzem, por diversas associações, à compreensão da realidade. À luz desse raciocínio, podemos entender que a elaboração ficcional do fantástico fornece apropriações e traços mínimos de associação com o mundo, sem os quais a viabilidade da transgressão do "ato de criar" não se efetivaria. Em outros termos, podemos entender que a fantasia da ficção não ocorre à revelia da realidade que a inspira, talvez porque, como nos lembra Edgar Morin, a espécie humana é a única que sonha "acordada".

A partir desse horizonte teórico, verificamos que exemplos de surrealismo em Império se sucedem: o sobrenatural se fez presente com o personagem Severo (Tato Gabus), ajudado por um garçom-fantasma, que o instigou a apostar no cavalo Falso Brilhante para ficar rico. O ocultismo surgiu a partir de um xamã, que preparou uma poção mística para forjar a morte do protagonista, o Comendador José Alfredo (Alexandre Nero). O personagem Jairo (Júlio Machado), ladrão e cúmplice de Cora, que foi assassinado, "retorna" em espírito para pedir a ajuda da mãe, Jurema (Elisângela). Maltrapilho e sujo de terra, o rapaz deixa uma trilha de bolsas femininas (porque ele roubava esse objeto das vítimas) para que a mãe siga e possa encontrar sua cova, depois de aparecer a ela diversas vezes em forma de sonho. Esse fato abre espaço na novela para a abordagem da mediunidade, outro tema recorrente nas criações de Aguinaldo Silva.

No intuito de discutir o contexto ficcional, adotando Império como espaço de reflexão e interlocução, apresentamos neste texto considerações sobre o papel da teledramaturgia enquanto eficiente instrumento de negociação de sentidos e vetor de disseminação cultural, cujas funções narrativas atuam como representações e mediações (MARTÍN-BARBERO, 2004) do cotidiano social. Nesse sentido, privilegiamos o aporte conceitual dos Estudos Culturais (JOHNSON, 2006) para compreender as influências da ficção televisiva (JOST, 2007; GORDILLO, 2010) nas leituras da realidade em seus mecanismos de verossimilhança, "nos quais vivemos uma segunda alfabetização: aquela que nos 
abre múltiplas escrituras que hoje conformam o mundo audiovisual" (MARTÍNBARBERO, 2014, p. 51).

\section{O fascínio da teledramaturgia: perspectivas conceituais}

A telenovela é um gênero ficcional que surgiu em 1963, definido como uma narrativa de serialidade longa, exibida diariamente, possuindo de 150 a 200 capítulos e permanecendo no ar por cerca de oito meses. A Rede Globo incorporou os modelos das emissoras pioneiras no gênero: a Tupi (1964-1980) e a Manchete (1984-1998), tornando-se a maior emissora de teledramaturgia transformando o país em um celeiro de arte, criatividade e talento, reconhecido no mundo através da exportação de suas tramas folhetinescas, "orientadas pelos arquétipos e símbolos que estruturam, atualizam e dinamizam o imaginário social" (PAIVA, 2010, p. 151).

Na percepção de Lopes (2009) trata-se de um produto estético e cultural que expressa a identidade do país, por combinar, em suas clivagens temáticas, o arcaico e o moderno, fundindo dispositivos narrativos anacrônicos e imaginários, "tendo sua história fortemente marcada pela dialética nacionalidade-midiatização. Trata-se de uma narrativa e de um recurso comunicativo que conseguem atuar nas representações culturais" (p. 22). Considerando esses termos, o gênero pode ser pensado enquanto matriz cultural de significação por se tratar de um construto que ativa na audiência competências técnicas e culturais por fomentar um repertório comum, que passa a ser de representações identitárias para ser compartilhado. Em síntese, as telenovelas geram reconhecimento, traduzem a realidade social e os próprios indivíduos (LOPES; BORELLI; RESENDE, 2002).

Para Johnson (2006), os Estudos Culturais apontam os eixos de subjetivação dos fenômenos, uma vez que buscam compreender as experiências socialmente localizadas e traduzidas mediante diversos dispositivos, incluindose os de cunho midiático como as telenovelas. Inseridas no âmbito dos produtos ficcionais, são consideradas poderosos veículos de narração histórica e representação da realidade sob o disfarce do "entretenimento". Se tratarmos 
esses produtos ficcionais como construções historicamente produzidas, abremse muitas possibilidades para um estudo produtivo de suas narrativas, "que se apresentam na conversação diária, nos futuros imaginados e nas projeções cotidianas de todos nós, bem como na construção - através de memórias e histórias - de identidades individuais e coletivas" (p. 69).

Lopes (2004) considera que a TV, por meio das narrativas ficcionais, retrata a sociedade contemporânea, devido à capacidade de alimentar um repertório cultural comum por meio do qual as pessoas de classes sociais, gerações, sexo, raça e regiões diferentes se posicionam e se reconhecem umas as outras. Para a autora, longe de promover interpretações consensuais, mas, antes, produzir lutas pela interpretação de sentido, esse repertório compartilhado está na base das representações de uma comunidade nacional "imaginada" que a TV capta, expressa e constantemente atualiza.

Com tal propósito, o poder das narrativas da ficção consiste em traduzir as tematizações sociais através de relações afetivas, ao nível do vivido, misturando-se na experiência cotidiana e revelando-se em múltiplas facetas: subjetiva, emotiva, política, cultural, estética. Nessa perspectiva, entendemos que a fusão dos domínios do imaginário e do real pela ficção, especialmente nas telenovelas, representa uma linha de força na construção de uma sociedade multicultural. Nesse sentido, a verossimilhança das tramas é tecida no interior da narrativa, o que permite o fortalecimento das raízes do gênero televisivo em meio à cultura que o produz, mobilizando a sensibilidade da audiência e promovendo o reconhecimento de fatos e/ou situações. A ficção televisiva tornase, assim, um lugar privilegiado de onde se anuncia uma nação representada e não só "imaginada".

Corroborando essa visão, Bulhões (2009) afirma: "A ficção não é um invólucro impenetrável, uma cápsula suspensa na imaterialidade: só pode transfigurar o real por tê-lo conhecido, por isso o subverte" (p. 22). Nos cenários da vida real, novas dimensões de sociabilidade são tecidas sob o signo das narrativas ficcionais, cujos personagens promovem modalidades de identificação, 
suscitando novos agenciamentos de sentidos, que fazem o público aceitá-los ou rejeitá-los. Quantas mulheres que veem a juventude se dissipar nos dramas cotidianos não desejariam colocar o "véu que rejuvenesce" responsável pela transformação da personagem Cora de Império?

No entanto, essas possíveis leituras da realidade devem ser embasadas. Gordillo (2010) salienta que para compreender os mecanismos de influência da ficção e suas relações com a sociedade, torna-se essencial conhecer as funções que perpassam o gênero. São elas: fabulização, a capacidade de atrair as pessoas para outros contextos, mediante a ação de personagens, tempos e espaços (por modos de representação popular); socializadora, ao unir grupos sociais em torno de temáticas comuns, gerando adesões, gostos e preferências; identitária, ao compartilhar os significados coletivos e as mutações culturais; disseminadora de modelos, ao organizar situações e personagens familiares, convertendo os estereótipos em sugestões de comportamento social; e formativa, no sentido de que alguns relatos expõem mensagens de cunho educativo.

Por isso, para Jost (2007), a ficção não representa uma mentira, mas traduz um olhar específico sobre a realidade. Ou seja: o real preexiste ao mundo inventado pelo escritor-dramaturgo e nada impede que ele se aproprie da realidade cotidiana para contar fatos imaginados. Em toda história verdadeira há elementos de ficção, que se unem para garantir verossimilhança ao que é narrado. "O jogo das tramas ficcionais é demasiado astucioso para ser apenas informação ou entretenimento" (p. 114).

A propósito da intenção de verossimilhança, Bulhões (2009) lembra que o artifício diz respeito à intenção de promover uma impressão de realidade. Tratase de um artifício antigo, que remonta à Poética de Aristóteles (384-322 a.C.), considerado o texto inaugural da literatura do Ocidente. A mimeses, termo grego para a condição de "imitação do real", gerou a noção de "representação" como a conhecemos hoje. Logo, com a liberdade da criação, o verossímil não está associado ao que ocorreu ou ao que existe, mas ao que poderia existir. 
Para além da verossimilhança, Lopes (2009) defende que as telenovelas repercutem expectativas e fomentam uma cultura de ecos, porque tão importante quanto o ritual diário de assistir aos capítulos é a informação e os comentários que atingem a todos do espaço social, mesmo àqueles que só de vez em quando as veem. As pessoas, independentemente de classe social, sexo, idade ou região, participam da circulação dos sentidos das tramas, em inúmeros circuitos onde estes são reelaborados e ressemantizados. Como muitos estudos ${ }^{7}$ evidenciam, as telenovelas começam a ser comentadas durante a sua assistência. Há também um poderoso núcleo de merchandising comercial e social 8 de cosméticos, carros, lojas, bancos e até campanhas públicas que repercutem porque abordam questões oportunas para o conhecimento coletivo. Por essas razões, a autora enfatiza que "o Brasil se vê nas telenovelas", e estas são consideradas ricos espaços de problematização social.

\section{Possíveis leituras da ficção televisiva: trilha metodológica para a percepção de sentidos}

As narrativas da ficção se entrecruzam e constituem material de análise que nos permitem verificar as intencionalidades que se escondem nas enunciações discursivas. Essas, por sua vez, engendram novas matrizes de sociabilidade no conhecidas através das instigantes pesquisas de Lopes (2009), e também dos significativos trabalhos de Ortiz, Borelli e Ramos Ortiz (1989), Campedelli (1985) e Fernandes (1994). Tais estudos se debruçam sobre as vinculações dessa problemática com outros campos de análise, a exemplo da Sociologia e Antropologia Cultural. A ficção também faz parte das pesquisas de Mousinho (2012), destacando-se o título A sombra que me move: ensaios sobre ficção e produção de sentido. 
cotidiano coletivo. As enunciações configuram os modos de dizer particulares de cada personagem, suas estratégias de comunicação, considerando as matrizes linguísticas que os caracterizam em virtude dos núcleos de cena que esses representam. Dessa forma, os processos enunciativos representam diferentes mecanismos de "modos de dizer" perpassados por suas intencionalidades. Nos diálogos, não buscamos um eco e uma mera ressonância, mas uma resposta, um efeito, uma reação. "A textura dialógica se encontra na constituição da subjetividade: o eu só se torna real na reciprocidade da interlocução, canal de mediação simbólica" (MARTÍN-BARBERO, 2014, p. 33).

São, portanto, as enunciações que dão vida aos diálogos e compartilham os sentidos, estabelecendo com o público os elos desejáveis entre produção/ recepção de mensagens, permitindo ainda que determinados "vícios" de linguagem sejam reproduzidos no espaço social. Em Império, o Comendador José Alfredo costuma mesclar em suas falas palavras da língua portuguesa (fortemente permeadas pelo seu sotaque nordestino) e inglesa, o que representa a transição de uma cultura "coloquial" para o desejo de uma possível "cultura letrada", alcançada pelas vias do empoderamento econômico e da ascensão social. Nessa perspectiva, as enunciações se tornam elos que aproximam o receptor das tematizações das obras ficcionais.

Motta (2007) demonstra que as enunciações da ficção podem ser "lidas e/ou desveladas" através do método de análise de narrativas, técnica que considera as histórias contadas e absorve, nas suas interpretações, as práticas culturais, atentando para os sentidos que as envolvem. É apropriada para os textos ficcionais, devido aos contextos pragmáticos que incorpora e ao aspecto sequencial que obedece. Assim, a narração é um recurso comunicativo que pressupõe, nos seus entremeios, uma estratégia textual mediante códigos, articulações sintáticas e pragmáticas, estruturando sequências encadeadas que pretendem comunicar algo comum aos receptores.

São várias as apropriações temáticas que as telenovelas realizam sobre a realidade social, como enfatiza Motter (2004). As narrativas fazem referências a 
tramas já conhecidas pelo público, recriam personagens de outros enredos, o que são considerados "empréstimos" discursivos, daí a necessidade de compreensão dos sentidos que instigam. Na produção ficcional, as narrativas possuem um eixo de articulação de histórias, em suas nuances secundárias ou essenciais, que formatam um novo texto composto por integrações, interpenetrações de fatos e encaixes sucessivos realizados entre atores, enredo e imagens.

Também observamos "doações" de fatos das novelas para o mundo real, como personagens que servem à publicidade, acessórios que migram da tela para o grande público, linguagens e músicas que capturam o gosto da audiência. Na visão de Sodré (2009) está em jogo uma nova fase da TV enquanto dispositivo semiótico de contato, para além de uma configuração perceptiva e afetiva do público, em que as capacidades de codificar e decodificar predominam sobre os conteúdos exibidos. Ou seja, o público tem sua atenção despertada pelas mensagens da ficção, construindo novos raciocínios e impressões a partir das narrativas. Para Mousinho (2012), "a narrativa não se exaure, conserva-se com poder de coesão, traz possibilidades de desdobramentos futuros" (p. 161).

Considerando que qualquer trilha metodológica não significa receita pronta e imutável, mas percurso aberto às possibilidades e percalços da investigação. De posse das perspectivas conceituais apropriadas, alguns eixos de análises ${ }^{9}$ são indicados aqui como sugestões:

- Identificar o tema central das telenovelas e os seus personagens situando-os nos núcleos dramáticos (contextos que representam determinados estratos sociais, indivíduos e estereótipos);

- Localizar e descrever os capítulos vinculados à temática-alvo de observação registrando os diálogos que compõem a noção de acontecimento narrativo (o que foi dito e como foi dito); 
- Observar as ambiências das tramas (cenários, objetos, figurinos, situações espaço-temporais), uma vez que essas são pensadas para produzir determinadas ações narrativas e alcançar efeitos específicos sobre a audiência.

As hipóteses de análise narrativa podem partir dos seguintes pressupostos, conforme mencionam Lopes, Borelli e Resende (2002):

- A telenovela é um produto ficcional híbrido;

- A telenovela possui uma matriz narrativa popular e ativadora de competências culturais;

- Existe um pacto de recepção entre o produto ficcional e a audiência: as construções de leitura são planejadas intencionalmente;

- O repertório compartilhado que a telenovela inspira não significa consenso de sentido, mas liberdade de interpretação. Essa possibilidade desconstrói o discurso da "manipulação" da mídia;

- A telenovela cumpre funções de agenda setting: temas são gerados a partir da ficção, inspirando novas leituras da realidade e alimentando outros veículos de comunicação (revistas, jornais, sites, blogs) (p. 36-37).

\section{(Pré) texto de conclusão}

Nesse jogo de mostrar e ocultar, sugerido pelo filósofo alemão nas entrelinhas do pensamento citado, as imagens da ficção são mediações culturais que, de acordo com as proposições de Martín-Barbero (2004), reinventam os lugares particulares de onde é possível pensar as interações ativas entre sociedade, espaços da produção e da recepção. Ou seja, os modos de ver ultrapassam o que é visto, são abertos a negociações decorrentes da própria trama cultural na qual os sujeitos sociais se encontram imersos. Falar de mediação, no sentido aqui colocado, implica considerar os processos de interpretação que ocorrem durante a percepção de uma trama ficcional e os modos de inteligibilidade que ela desperta, inseridos nas 
suas estratégias de comunicabilidade narrativa. Por isso, essa assertiva nos parece apropriada: "temos que estudar não o que fazem os meios com as pessoas, mas o que fazem as pessoas com elas mesmas, o que fazem com os meios, quais são suas leituras" (p. 55). Logo, cada enredo da ficção guarda uma espécie de "manual de uso", que é socialmente reconhecido e aceito legitimamente pelos telespectadores a partir de uma intensa dinâmica de negociação de sentidos.

Sodré (2009) argumenta que da TV "parte influência emocional e sensorial, onde identidades pessoais, comportamentos e juízos passam pelo crivo público" (p. 44). Essa influência é a alma do processo de midiatização, pois instiga identificações e pertencimentos. Dessa maneira, inicia-se um processo de autoconstrução de subjetividades que ressignificam as mediações ficcionais. A cumplicidade das tramas com os consumidores de suas ideias permite aos textos e roteiros a popularização das expectativas humanas. Como decorrência, a novela é mesclada com o real, e as fronteiras do imaginário se fundem com os desejos da sociedade. Defendendo essa ideia, Borelli, Figueiredo e Gomes (2009) defendem que as novelas se propõem a atingir, a um só tempo, coração, olhos e ouvidos. A contraposição entre o bem e o mal, ricos e pobres, justos e injustos sensibiliza o público e cativa a sua atenção. Talvez por isso o rejuvenescimento da personagem Cora, em Império, foi "legitimado" com naturalidade, ao invés de provocar a rejeição da audiência.

Consideradas por muito tempo um gênero massivo feminino, as novelas contemporâneas seduzem ao mostrarem trajetórias complexas de anti-heróis, como o caso do protagonista de Império, cujo comportamento afetivo nos conduz a pensar em outras formas de inteligibilidade das relações sociais e familiares. Em virtude de ser um produto voltado para a comercialização de bens e ideias, o formato narrativo não pode desconsiderar as mudanças ocorridas com o público masculino ao longo das décadas. Hoje, os personagens escolhidos como protagonistas, em substituição às heroínas dos primeiros folhetins televisivos, traduzem novos modelos de personalidade, mostram-se ambivalentes, sensíveis, afetivos e participativos em sintonia ao atual modelo 
social dos arranjos familiares. São protagonistas que fogem aos estereótipos do "machão sem alma e sentimentos", embora exponham tanto vilanias quanto fragilidades, mesclando em ações inusitadas os arquétipos "do bem e do mal", como dita a velha fórmula dos dramas ficcionais.

Os recursos surreais, por sua vez, revelam mecanismos de intertextualidade, analogias e paródia, percebidos quando um texto depende de outro para adquirir validade e existência. Em outras palavras, as paródias, por exemplo, assimilam procedimentos narrativos comuns a outros textos, que são facilmente identificáveis (BULHÕES, 2009), como ocorre nas produções anteriores desse dramaturgo. Império, nesse sentido, revela marcas de distinção autoral e de similaridade temática, quando o ato criador na ficção é associado a estilos próprios ${ }^{10}$ (SOUZA; OROFINO; RIGHINI, 2009).

Assim, quanto mais se conhece as práticas de produção e apropriação das telenovelas, maiores condições existem para estabelecer as hipóteses interpretativas sobre as escolhas narrativas e textuais operadas pelos autores das tramas, devido às marcas autorais de cada um. Desse modo, os personagens "operam estratégias de reconhecimento coletivo que, a partir da reiteração dos elementos narrativos, acabam por proporcionar ao espectador um sentido de verdade e similaridade ao que vê" (FECHINE; FIGUEIROA, 2009, p. 367). Por fim, percebendo a teledramaturgia a partir de uma lógica multifocal, que considera seu poder de mediação e interlocução com o cotidiano, torna-se possível identificar não apenas os estilos textuais das tramas, como também as maneiras de desconstrução das sociabilidades, das discursividades, das paródias e estereótipos, dos dramas amorosos e familiares, que dia após dia atraem e enredam a audiência, mantendo-a na expectativa prazerosa dos próximos capítulos. Afinal, é tudo isso que faz a magia da ficção. 


\section{Referências}

ALMEIDA, M. da C. de. Por uma ciência que sonha. In: GALENO, A. ; CASTRO, G. de; SILVA, J. C. da (Orgs.). Complexidade à flor da pele: ensaios sobre ciência, cultura e comunicação. São Paulo: Cortez, 2003.

BORELLI, S. H.; FIGUEIREDO, A. M. C.; GOMES, M. Narrativas da juventude e do feminino. In: LOPES, M. I. V. de (Org.). Ficção televisiva no Brasil: temas e perspectivas. São Paulo: Globo, 2009.

BULHÕES, M. A ficção nas mídias: um curso sobre a narrativa nos meios audiovisuais. São Paulo: Ática, 2009.

CARVALHO, E. de A. Repensar a vida, uma necessidade inadiável. In: GALENO, A. ; CASTRO, G. de; SILVA, J. C. da (Orgs.). Complexidade à flor da pele: ensaios sobre ciência, cultura e comunicação. São Paulo: Cortez, 2003.

FECHINE, Y.; FIGUEROA, A. Produção ficcional brasileira no ambiente de convergência: experiências sinalizadoras a partir do Núcleo Guel Arraes. In: LOPES, M. I. V. de (Org.). Ficção televisiva no Brasil: temas e perspectivas. São Paulo: Globo, 2009.

GALENO, A.; CASTRO, G. de; SILVA, J. C. da (Orgs.). Complexidade à flor da pele: ensaios sobre ciência, cultura e comunicação. São Paulo: Cortez, 2003.

GORDILLO, I. Manual de narrativa televisiva. Madrid: Sintesis, 2010.

IMPÉRIO. Direção de Rogério Gomes. Roteiro de Aguinaldo Silva. Rio de Janeiro: Rede Globo, 2014.

INDOMADA, A. Direção de Marcos Paulo. Roteiro de Aguinaldo Silva; Ricardo Linhares. Rio de Janeiro: Rede Globo, 1992. 
JOHNSON, R. O que é, afinal, Estudos Culturais? In: JOHNSON, R.; ESCOSTEGUY, A. C.; SCHULMAN, N. O que é, afinal, Estudos Culturais? Belo Horizonte: Autêntica, 2006.

JOST, F. Compreender a televisão. Porto Alegre: Sulina, 2007.

LOPES, M. I. V. de; BORELLI, S. H. S.; RESENDE, V. da R. (Orgs.). Vivendo com a telenovela: mediações, recepção, teleficcionalidade. São Paulo: Summus, 2002.

LOPES, M. I. V. de. Para uma revisão das identidades coletivas em tempos de globalização. In:

(Org.). Telenovela: internacionalização e interculturalidade. São Paulo: Loyola, 2004.

. Telenovela como recurso comunicativo. Revista Matrizes, v. 3, n. 1, p. 21-47, ago./dez., 2009.

MARTÍN-BARBERO, J. Dos meios às mediações. Rio de Janeiro: UFRJ, 2004.

. A comunicação na educação. São Paulo: Contexto, 2014.

MOTTA, L. G. Análise pragmática da narrativa jornalística. In: LAGO, C.; BENETTI, M. (Orgs.). Metodologia de pesquisa em jornalismo. Petrópolis: Vozes, 2007.

MOTTER, M. L. Mecanismos de renovação do gênero telenovela: empréstimos e doações. In: LOPES, M. I. V. de (Org.). Telenovela: internacionalização e interculturalidade. São Paulo: Loyola, 2004.

MOUSINHO, L. A. A sombra que me move: ensaios sobre ficção e produção de sentido (cinema, literatura, TV). João Pessoa: Ideia, 2012.

PAIVA, C. C. de. Dionísio na Idade Mídia: estética e sociedade na ficção televisiva seriada. João Pessoa: UFPB, 2010. 
PEDRA SOBRE PEDRA. Direção de Paulo Ubiratan. Roteiro de Aguinaldo Silva; Ricardo Linhares; Ana Maria Moretsohn. Rio de Janeiro: Rede Globo, 1992.

SODRÉ, M. Antropológica do espelho: uma teoria da comunicação linear e em rede. Petrópolis: Vozes, 2009.

SOUZA, M. C. J.; OROFINO, I.; RIGHINI, R. R. Criadores na dramatização da juventude, do feminino e da pobreza. In: LOPES, M. I. V. de (Org.). Ficção televisiva no Brasil: temas e perspectivas. São Paulo: Globo, 2009.

TIETA. Direção de Paulo Ubiratan. Roteiro de Aguinaldo Silva; Ana Maria Moretsohn; Ricardo Linhares. Rio de Janeiro: Rede Globo, 1989.

submetido em: 04 fev. 2015 | aprovado em: 28 abr. 2015 